\title{
The Implementation of an Expert Pharmacotherapeutic Information System in Bulgaria - Perspectives and Challenges
}

\section{Svetlana Galeva* and Natasha Danova}

National Center of Public Health and Analyses, Sofia, Bulgaria

*Corresponding author: Svetlana Galeva, National Center of Public Health and Analyses, 15 Ac. I. E. Geshov Bul, Sofia 1431, Sofia, Bulgaria, Tel: +359 2 8056444; Email: sv.galeva@gmail.com

Received date: Aug 18, 2017; Accepted date: Aug 31, 2017; Publish date: Sep 08, 2017

Copyright: (c) 2017 Galeva S, et al. This is an open-access article distributed under the terms of the Creative Commons Attribution License, which permits unrestricted use, distribution, and reproduction in any medium, provided the original author and source are credited.

\begin{abstract}
The implementation of expert information systems in healthcare is a way to achieve better care for the patients, as well as effective management of the healthcare sector. The electronization of the drug therapy process brings a lot of advantages-time and resources are spared, the patient's treatment plan is optimized and the engagement of the patient and their satisfaction with the medical service increases. The implementation of a pharmaco-therapeutic information system in Bulgaria is based on the experience of some European countries with similarly functioning systems, as well as the good practices in this field. Despite some difficulties, accompanying its implementation, the basic functionality of the system will provide support to professionals in deciding on their patients' drug therapy. Upgrading and improving the system in the coming years will lead to a greater degree of refinement and individualization of medical prescriptions.
\end{abstract}

Keywords: Pharmaco-therapeutic; e-health; e-prescription

\section{Introduction}

The utilization of medical guides and pharmaco-therapeutic manuals to support clinical decisions has been an established practice for decades. With the introduction of digital technologies in healthcare, attempts are being made to develop information systems that link resources of different origins to provide the best computer "action plan" for the diagnosis and treatment of a particular disease. The deployment of this type of information system brings a number of advantages and tools to medical specialists and patients and results in an overall improvement in the quality of the medical service.

Although the communication technologies sector is one of the most dynamically developing in Bulgarian economy (with a contribution of $4.5 \%$ to the total gross value, at $3.7 \%$ on average for the European Union) [1], information Healthcare systems in Bulgaria are still fragmented and only locally active. The lack of a national integrated system that unifies health information and standardizes healthcare processes creates barriers for system participants and prevents the strategic management of the sector. Therefore, the launch of the first two stages of the development of the National Health Information System (NHIS) and the idea of including an expert pharmacotherapeutic system in it gives hope for a qualitatively new level of medical care in Bulgaria. In countries where such systems operate, there is a significant decline in drug-related risks in terms of indications, effectiveness and safety, as well as a significant increase in patient satisfaction [2].

\section{Purpose}

The purpose of this article is to present the concept of implementing an expert pharmaco-therapeutic system as a module from the Integrated National Health Information System (NHIS) in Bulgaria, as well as to highlight some risks to the successful System operation and display how much it reflects the results achieved and follows the good practices in this field.

\section{Materials and Methods}

A historical method is used to describe the process of deploying expert pharmaco-therapeutic systems in some European countries. Publications presenting real projects and research studies, as well as official online information on the NHIS development project were also utilized.

\section{Results and Discussion}

Effective health care management, in addition to the social dimension, also operates in an economic and political dimension. Sometimes the procedures recommended by the healthcare professional may not be the most appropriate for a particular patient. The guidelines included in medical manuals and drug directories often do not reflect the accumulated database in individual hospital servers, concerning clinical practice cases, nor do they keep up-to-date given the accelerated insertion of new drugs into the market. The influence of health insurance companies also increases in the decision what treatment to be assigned in a particular medical condition. The achievement of a successful outcome for the patient at a lower cost is in the public interest. In order to ensure a better level of healthcare management, modern IT solutions provide expert computer systems for interactive support to the user in solving specific professional problems. Such a type of system can be implemented using a relational database and graphical interface to retrieve data and references. Dynamic decision support provides information and action recommendations by hierarchically arranging individual cases and creating a response pattern for a particular clinical situation. Medical guides and drug directories can be set centrally, distributed electronically and used locally to ensure sustainability in the decisionmaking process by the healthcare professional [3]. 
With the advent of new technologies, projects are designed to digitalize the diagnosis process and choose drug therapy begins. An attempt in developing such a system was first made in Sweden. The use of computerized prescription and drug delivery management systems started in the 1970s with several local computerized systems for introducing handwritten prescriptions and forming local registers of medical prescriptions. The first e-prescription was sent by a general practitioner to a pharmacy in the distant 1983 . The next year, the first online recipe was implemented as part of a pilot project. Three years later software was designed to record prescriptions on the smart card of the patient [4]. The search for the most effective solution goes through the constant incorporation of different information systems, as well as the handling of various medical, technological and social problems. In the period 1986-1988 the Drug Assistance System (developed by the local "Infocard") was developed and utilized in some medical practices. Its algorithm of work began with a choice of diagnosis, selection of a subclass, and review of general information on the disease. A thorough review followed: of the section of drug groups applicable to the health problem, choice of pharmaceutical group, choice of active ingredient, product name and dosage form. At this stage, a check is made in the patient dossier for established allergies and if the selected medicinal product is incompatible, the system sends back the medical specialist to the previous stage to choose a different active drug. The doctor has the opportunity to review the pharmacological information available in the system, then fill in the prescription form and record the prescription on the patient's electronic card [5]. The system enables medical specialists to choose an interactive treatment for a particular patient according to the specific diagnosis and the patient's state of health, established allergic reactions and other personal characteristics, choosing from the full range of registered medicinal products in that country. It maintains a database of pharmacological information that the medical practitioner has access to and can use if desired. The system is considered to be innovative in several areas, but the main is the use of several databases in the spelling of medicines-a drug directory, a database of registered medicinal products in the country and a pharmacological information database.

In Bulgaria, there are still no expert systems in place to integrate national databases but the development and implementation of a system with basic functions will be developed and will be expanded and upgraded in the coming years. Aside from the experience of the early models of such a system, the development of expert pharmacotherapeutic systems in other European countries has also been explored in order to use appropriate algorithms that conform to current standards and apply good practices in the implementation of the project. The implementation of the first two stages of the development of the National Health Information System (NHIS)-the basic e-health system in the country, is underway [6]. Along with the development and introduction of an electronic health record, electronic recipe, e-mail, registers and others, in the start-up functionality of NHIS an Expert Pharmacotherapeutics System (EPS) will be implemented as a module to support medical and pharmaceutical specialists in determining an appropriate therapy and effective treatment to their patients [7]. By the end of 2018, EPS will be integrated into the NHIS and will be located in the State Private Hybrid Cloud, with medical service providers providing Web access to it [8].

The embedded EPS should maintain analytical, control, reference and advisory functions. The system will support and control clinical decisions, display the maximum daily doses of active drug substance, incompatible prescriptions, adverse drug reactions etc. Its reference functionality will be based on a comprehensive, up-to-date, reliable database of all medicinal products authorized for use on the Bulgarian market and the current pharmaco-therapeutic manuals for medical specialties. A serious challenge to the system's performance is to maintain complete and up-to-date information in the databases used. Authorization for use of medicinal products in Bulgaria is issued by the Medicines Executive Agency, a state institution, subordinate to the Ministry of Health. The Agency maintains a register of authorized medicines, as well as information on publicly available medicines, and allows the reporting of adverse reactions by healthcare professionals but without providing access to aggregated data on the reported complications [9]. There is no pharmacological or pharmacotherapeutic information on the website and an electronic drug guide for general practitioners, for example, is not available. The updates of lists and registers are periodic rather than real-time, making the process difficult for the users. The problem with the up-to-date data is creatively resolved in Italy-a group of universities are involved in the process, ensuring timely updates of the information [10].

\section{Conclusion}

The introduction of expert pharmaco-therapeutic information systems has social, ethical and economic dimensions. In addition to saving time and resources, systems optimize drug therapy and help create an individualized and disease-appropriate treatment plan [11]. By following the interactive decision-making model, the patient's commitment to the treatment process and their satisfaction with the medical service are increased.

The NHIS project module combines the beneficial experience of countries using expert pharmacotherapy systems and follows the good practices in the field. Its development will provide a higher level of health care at a lower cost.

\section{References}

1. http://www.nsi.bg/en

2. De Oliveira DR, Brummel AR, Miller DB (2010) Medication Therapy management: 10 Years of experience in a large integrated health care system. J Manag Care Pharm 16: 185-195.

3. McAndrew PD, Potash DL, Higgins B, Wayand J, Held J, et al. (1996) Expert system for providing interactive assistance in solving problems such as health care management, US 5517405.

4. Öhlund SE, Astrand B, Petersson B (2012) Improving interoperability in ePrescribing. Interact J Med Res 1: e17.

5. Klein GO (2011) History of electronic prescription in Sweden: From time-sharing Systems via Smartcards to EDI. History of Nordic Computing 3: 65-73.

6. http://www.mh.government.bg/bg/novini/aktualno/ministerstvoto-nazdraveopazvaneto-poluchi-12-mili/

7. https://www.mh.government.bg/media/filer_public/2016/10/07/ izgrazhdane_na_ekspertna_farmako_terapevtichna_sistema_efts.pdf

8. https://www.e-gov.bg/bg/88

9. http://www.bda.bg/bg/

10. Krasteva N (2013) IT in healthcare around the world-role models. CIO: E-Health.

11. Woolf SH, Grol R, Hutchinson A, Eccles M, Grimshaw J (1999) Potential benefits, limitations, and harms of clinical guidelines. BMJ 18: 527-530. 